\title{
Tumor Lysis Syndrome in Solid Tumors: A Comprehensive Literature Review, New Insights, and Novel Strategies to Improve Outcomes
}

\author{
Dawood Findakly ${ }^{1}$, Ross D. Luther III ${ }^{2}$, Jue Wang ${ }^{3}$ \\ 1. Internal Medicine, Creighton University Arizona Health Education Alliance/Valleywise Health Medical Center, \\ Phoenix, USA 2. Urology, Madigan Army Medical Center, Tacoma, USA 3. Genitourinary Oncology, Creighton \\ University School of Medicine/University of Arizona Cancer Center at Dignity Health, Phoenix, USA
}

Corresponding author: Jue Wang, jue.wang@dignityhealth.org

\begin{abstract}
Tumor lysis syndrome (TLS) is a life-threatening oncological condition that is typically characterized by metabolic derangements that are often labeled as an acute kidney injury. The recent advancement in cancer treatment has led to the mounting rate of TLS in solid tumors that were previously rarely linked to this complication. Given that its prognosis is dismal, it is essential to increase recognition of this condition by describing more sensitive markers. Currently, the management of TLS is mainly supportive due to the lack of specific therapy targeting its specific pathology. This review aims to summarize the most recent literature on the underlying mechanism of TLS and the potential implications for novel TLS therapy.
\end{abstract}

Categories: Emergency Medicine, Internal Medicine, Oncology

Keywords: tumor lysis syndrome, solid tumors, new insights, literature review, autopsy, disseminated intravascular coagulation (dic), cytokine storm syndrome

\section{Introduction And Background}

Tumor lysis syndrome (TLS) is a life-threatening medical condition that can occur spontaneously or as a complication of cancer therapy for rapidly proliferating and chemo-sensitive malignancies such as acute lymphoblastic leukemia or high-grade lymphoma [1-3]. The devastating outcomes of TLS arise from rapid tumor cell lysis and the release of metabolites into the systemic circulation, therefore, leading to potentially fatal metabolic abnormalities, including hyperkalemia, hyperphosphatemia, hyperuricemia, and hypocalcemia [1].

A definitive TLS diagnosis requires one clinical and two laboratory criteria. Laboratory TLS is characterized by one of three scenarios. The first two are in the setting of a normal uric acid where a deranged phosphate and potassium levels, either exceed the upper limit of normal (ULN) or exhibit at least a $25 \%$ increase from normal levels. The third scenario is where uric acid exceeds the ULN or shows a $25 \%$ increase from baseline, including either elevated potassium or phosphate levels simultaneously. Coupled with these laboratory findings are many clinical criteria that often present as results of the underlying electrolyte abnormalities and accumulation of toxic metabolites within the blood. One key finding is creatinine elevation greater than or equal to 1.5 times the ULN, which may manifest as oliguria or anuria. Other common findings include cardiac arrhythmias and/or sudden death because of hyperkalemia [2-4].

๑) Copyright 2020 Findakly et al. This is an open access article distributed under the terms of the Creative Commons Attribution License CC-BY 4.0., which permits unrestricted use, distribution, and reproduction in any medium, provided the original author and source are credited.
Interestingly, acute kidney injury (AKI) may result from the deposition of uric acid or calcium phosphate crystals within renal tubules. AKI, besides hyperphosphatemia-driven hypocalcemia, can cause tetany and seizures $[1,3,5,6]$. Although reported in cases, physicians' unscripted remarks labeling the forementioned renal consequences as an AKI is what contributes to the underestimated true incidence of TLS [3]. Given the high mortality of TLS, it is necessary to improve clinician awareness via the identification of more sensitive markers for this condition. This review aims to summarize the growing body of literature regarding TLS explicitly and to review relevant pathophysiological mechanisms to understand this syndrome better, therefore, ultimately, expand the depth of expertise and to pave the way to future evidence-based guidelines in order to find new standardized strategies for TLS prophylaxis and treatment.

\section{Review}

\section{Incidence of TLS in solid tumors}

TLS typically occurs in patients with acute lymphoblastic leukemia (ALL) and non-Hodgkin lymphoma (NHL). The incidence of TLS comprises about 10\% among patients undergoing remission-induction chemotherapy $[7,8]$. It is essential to recognize that the relatively recent and ongoing progress in cancer therapy has led to the rising incidence of TLS in solid tumors that were previously rarely thought to be associated [3]. The importance of this progress lies in the observation that mortality for TLS stemming from solid tumors is moderately high at $35 \%$ compared to $1.9 \%$ rate reported for patients with ALL and NHL 


\section{Cureus}

$[1,4,9-17]$.

\section{Current understanding of TLS}

An expanding body of research centered on the pathophysiology of TLS is utilized in order to understand its relation to clinical outcomes. Traditionally, AKI has been cited as the most common cause of death in patients with TLS due to solid tumors [10]. Risk factors for TLS are well-documented in the literature and are primarily driven by high tumor burden as defined by elevated lactate dehydrogenase, elevated white blood cells, bulky disease, high proliferation rate, and organ metastases [18-20]. Moreover, advanced age predisposes to TLS, as it correlates with a reduction in decreased glomerular filtration rate and heightened susceptibility to dehydration [3].

\section{New insight of TLS}

Animal Models: Understanding the Pathophysiology of TLS

Despite the aforementioned predisposing factors, animal models of TLS have shown resilience in some mice with heavy tumor burdens, suggesting that heavy tumor burden itself is necessary but not sufficient to cause TLS. This has notably prompted efforts to investigate further pathophysiologic mechanisms of tissue damage that may explain the high mortality of TLS [21-25]. For example, studies in mice revealed that disseminated microemboli composed of debris from lysed tumor cells prompted mechanical microobstruction of multiorgan capillary beds, including the kidney tubules, brain, lungs, and elsewhere. These processes ultimately resulted in widespread tissue ischemia, necrosis, and early death [21,22]. This finding proposes an alternative to the classic picture of TLS-driven AKI through renal tubular crystal deposition. On the other hand, this may suggest several potential mechanisms for developing AKI. This further proposed a possible synergistic process through a microemboli-driven decreased renal perfusion resulting in oliguria and tissue hypoxia, which subsequently promote crystal deposition and necrosis of the renal tubular epithelium (Table 1). Finally, the dissemination of microemboli may underlie the other nonspecific clinical signs associated with TLS in humans, such as respiratory distress and mental status changes. 


\section{Cureus}

\begin{tabular}{|c|c|c|c|c|c|c|c|c|}
\hline Author & $\begin{array}{l}\text { Experimental } \\
\text { Model }\end{array}$ & $\begin{array}{l}\text { Treatment Type vs. } \\
\text { Spontaneous }\end{array}$ & $\begin{array}{l}\text { Cancer } \\
\text { Pathology }\end{array}$ & Metastases & $\begin{array}{l}\text { Microemboli } \\
\text { Composition }\end{array}$ & $\begin{array}{l}\text { Post-Mortem } \\
\text { Pathology }\end{array}$ & $\begin{array}{l}\text { Clinical } \\
\text { Presentation }\end{array}$ & Ref \\
\hline $\begin{array}{l}\text { Lovelace et } \\
\text { al. }\end{array}$ & $\begin{array}{l}\text { Case Report: } \\
\text { 10-month-old } \\
\text { female } \\
\text { sentinel } \\
\text { mouse }\end{array}$ & STLS & $\begin{array}{l}\text { Leukemic } \\
\text { lymphoma }\end{array}$ & $\begin{array}{l}\text { Cranial, liver, } \\
\text { spleen, and } \\
\text { mediastinal, } \\
\text { submandibular, } \\
\text { and mesenteric } \\
\text { LN }\end{array}$ & $\begin{array}{l}\text { Mixed } \\
\text { eosinophilic } \\
\text { and } \\
\text { basophilic } \\
\text { (aggregated } \\
\text { chromatin) } \\
\text { NNC }\end{array}$ & $\begin{array}{l}\text { Embolic } \\
\text { vascular } \\
\text { occlusions } \\
\text { within the } \\
\text { lungs, } \\
\text { kidneys, } \\
\text { brain, liver }\end{array}$ & Seizure & [21] \\
\hline Vogel et al. & $\begin{array}{l}\text { RCT: } \\
\text { p53 } 3^{+-} \text {mice } \\
\text { (50\% female, } \\
50 \% \text { male) }\end{array}$ & STLS & $\begin{array}{l}\text { Disseminated } \\
\text { lymphoblastic } \\
\text { lymphoma } \\
\text { and leukemia, } \\
\text { bladder } \\
\text { neoplasia }\end{array}$ & $\begin{array}{l}\text { Spleen, liver, } \\
\text { multiple LN } \\
\text { chains }\end{array}$ & $\begin{array}{l}\text { Mixed } \\
\text { basophilic } \\
\text { (aggregated } \\
\text { chromatin) } \\
\text { and } \\
\text { eosinophilic } \\
\text { NNC }\end{array}$ & $\begin{array}{l}\text { Microembolic } \\
\text { occlusions } \\
\text { within liver, } \\
\text { lung, brain }\end{array}$ & NM & [22] \\
\hline Calia et al. & $\begin{array}{l}\text { Case Report: } \\
\text { 2-year-old } \\
\text { female } \\
\text { domestic } \\
\text { short hair cat, } \\
\text { feline } \\
\text { leukemia } \\
\text { virus-positive }\end{array}$ & $\begin{array}{l}\text { Chemotherapy: IP } \\
\text { injection L-asparaginase } \\
\text { ( } 400 \text { mg/kg), prednisone ( } 5 \\
\text { mg PO bid) Radiation: } \\
\text { Cobalt } 60 \text { teletherapy, } 800 \\
\text { cGy }\end{array}$ & Lymphoma & $\begin{array}{l}\text { Brain, and } \\
\text { mediastinal } \\
\text { mass }\end{array}$ & N/A & N/A & $\begin{array}{l}\text { Respiratory } \\
\text { failure, } \\
\text { arrhythmia }\end{array}$ & [23] \\
\hline $\begin{array}{l}\text { LaCarrubba } \\
\text { et al. }\end{array}$ & $\begin{array}{l}\text { Case Report: } \\
\text { 11-year-old } \\
\text { mare (female } \\
\text { horse) }\end{array}$ & STLS & $\begin{array}{l}\text { Peritoneal } \\
\text { mesothelioma }\end{array}$ & $\begin{array}{l}\text { Direct } \\
\text { extension into } \\
\text { thoracic cavity }\end{array}$ & $\begin{array}{l}\text { High-grade } \\
\text { neoplastic } \\
\text { cells staining } \\
\text { positive for } \\
\text { cytokeratin } \\
\text { and vimentin }\end{array}$ & $\begin{array}{l}\text { Myxomatous } \\
\text { degeneration } \\
\text { of ascending } \\
\text { aorta, main } \\
\text { pulmonary } \\
\text { artery }\end{array}$ & $\begin{array}{l}\text { SIRS, MOF, } \\
\text { arrhythmia, } \\
\text { RF }\end{array}$ & [24] \\
\hline $\begin{array}{l}\text { Mylonakis } \\
\text { et al. }\end{array}$ & $\begin{array}{l}\text { Case Report: } \\
\text { 5-year-old } \\
\text { female } \\
\text { German } \\
\text { Shepherd dog }\end{array}$ & $\begin{array}{l}\text { Chemotherapy } \\
1^{\text {st }} \text { protocol: } \\
\text { Cyclophosphamide, } \\
\text { vincristine, cytosine, } \\
\text { arabinoside, prednisolone. } \\
\text { Chemotherapy } \\
2^{\text {nd }} \text { protocol: Vincristine, } \\
\text { L-asparaginase, } \\
\text { prednisolone, } \\
\text { cyclophosphamide, } \\
\text { doxorubicin. }\end{array}$ & $\begin{array}{l}\text { B-cell } \\
\text { multicentric } \\
\text { lymphoma }\end{array}$ & N/A & N/A & N/A & $\begin{array}{l}\text { MOF, DIC, } \\
\text { RF }\end{array}$ & [25] \\
\hline
\end{tabular}

\section{TABLE 1: Review of TLS in animal model findings}

RCT: Randomized controlled trial; TLS: Tumor lysis syndrome; STLS: Spontaneous TLS; LN: Lymph nodes; NNC: Necrotic neoplastic cells; NM: Not mentioned; N/A: Not applicable; MOF: Multi-organ failure; RF: Renal failure; DIC: Disseminated intravascular coagulation; Ref: Reference.

Human Autopsy Studies

Several documented case reports of TLS in humans appear to echo animal model findings, as microemboli appear to play a direct role in widespread tissue damage [20-34]. The demographics, clinicopathologic features, autopsy findings, and outcomes are summarized in Table 2. Takeuchi et al. reported rapid decompensation within 40 hours of admission in a patient with spontaneous TLS secondary to malignant melanoma. Interestingly, the autopsy revealed a key finding of massive necrosis of normal hepatocytes and melanoma cells within the liver as well as disseminated tumor thrombi in the portal system. Additionally, they found extensive necrosis within a large pulmonary tumor [26]. Moreover, similar findings were reported by Kearney et al. where an autopsy in a patient with STLS revealed extensive tumor necrosis, widespread tumor thrombi in portal venous branches, pulmonary tumor deposits, and near-total replacement of lymph nodes with tumor and necrosis [27]. These findings indicate that TLS stemming from a solid tumor likely 


\section{Cureus}

induces necrosis within both tumor and non-tumor cells that are distant from the tissue of origin. Ito et al. reported a patient with TLS following docetaxel and carboplatin treatment for recurrent endometrial cancer. This patient developed classic laboratory abnormalities for TLS, AKI, in conjunction with sudden onset chest pain, hypoxia, and respiratory distress 19 hours after initiation of chemotherapy, and the autopsy, thereafter, showed pulmonary tumor embolism [28]. 


\section{Cureus}

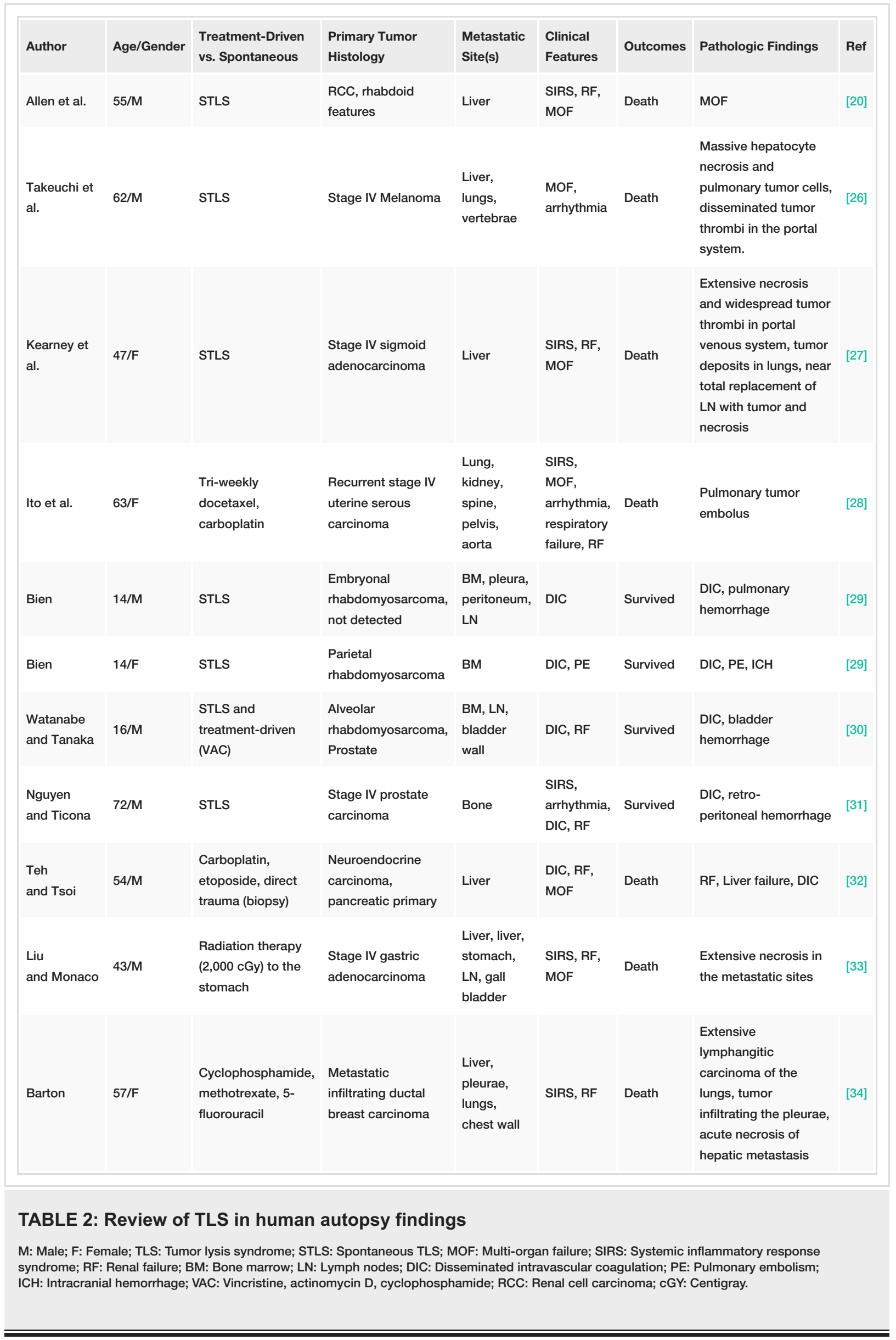


The association between DIC and neoplasms is well-known and is not uncommon. DIC is estimated to present in 15-20\% of patients with acute leukemia, specifically the acute promyelocytic leukemia (APL) variant, and $7-15 \%$ of patients with solid metastatic tumors [23]. Several reports in the literature support the hypothesis that TLS and DIC were co-occurring, with one seemingly providing a nidus for the other and contributing to a rapid synergistic decline in patients' hemodynamic status. Watanabe and Tanaka presented a case of a 16-year-old Japanese male who developed prostate rhabdomyosarcoma with multiple bony metastases and found to have laboratory TLS findings upon initial evaluation. The patient subsequently developed DIC just one week following biopsy. Rasburicase administered on day 1 of chemotherapy initiation. On day 3 of treatment, the patient developed a worsening of his DIC secondary to tumor lysis, and the patient ultimately recovered due to early recognition of TLS [30]. A similar instance of concurrent TLS and DIC reported in a case of untreated prostate cancer with widely metastatic bony metastases [31]. In this case, the patient developed spontaneous TLS with subsequent worsening of DIC but fully recovered due to early initiation of rasburicase and appropriate supportive care. Another case of concurrent TLS and DIC was reported in a patient with metastatic neuroendocrine carcinoma following manipulation by core biopsy and then again following the initiation of cytotoxic chemotherapy [32]. The significance of these presentations lies in the common pathogenesis as pro-inflammatory cytokines mediate both TLS and DIC.

The Role of Hypercytokinemia in TLS

Further complicating the management of TLS, clinicians must be aware of the potential of hypercytokinemia, or cytokine storm as a consequence of cancer treatment and how this may necessitate alternate therapy modalities to address systemic inflammatory response syndrome (SIRS) and multi-organ failure (MOF). Hypercytokinemia involves the release of intracellular cytokines (e.g., TNF-alpha, IL-6, IL10 ), which induces SIRS leading to MOF and hemodynamic instability marked by hypotension and tachycardia [35-38]. Hsu et al. and Schonbohn et al. found increased blood levels of IL-6, IL-8, IL-1, and TNF-alpha following single courses of chemotherapy for acute myelogenous leukemia (AML) [39,40]. Born out of these findings came the hypothesis that TLS may be the driver for cytokine storm, as rapid cell lysis causes the release of these pro-inflammatory cytokines which collectively induce nitric oxide-mediated vasodilation and systemic inflammation. Interestingly, IL-1, IL-6, and TNF-alpha may contribute to DIC via the induction of the hepatic release of clotting factors (e.g., fibrinogen) and other acute-phase reactants (e.g., C-reactive protein), culminating in SIRS and MOF. For instance, Nakamura et al. observed four patients with baseline renal dysfunction who developed TLS within two days of chemotherapy initiation, $100 \%$ of which progressed to kidney failure and 50\% to MOF. Key findings from this study include: (1) elevated serum IL-6 levels in $100 \%$ of cases with a blood level tended to be proportional to the increase in the numbers of organs failing; (2) the serum levels of other cytokines (TNF-alpha, IL-8 and IL-10) were elevated in one of the cases; and (3) all patients survived following 3-7 days of polymethylmethacrylate membrane continuous hemodiafiltration (PMMA-CHDF) for cytokine removal [36]. Similarly, Soares et al. observed five patients with confirmed TLS via both spontaneous $(n=2)$ and chemotherapy-driven mechanisms $(n=3)$ who all fulfilled SIRS criteria and had at last three distinct organ dysfunctions (e.g., respiratory, renal, hepatic). All patients required ventilator support, and $80 \%$ treated with renal replacement therapy. Among those patients, $40 \%$ ultimately died, with $2 / 3$ of the surviving patients regaining full renal function [37].

The question remains as to the temporal relationship between TLS and cytokine storm, but the comorbidity and interplay of processes cannot be ignored. Hyperuricemia itself, a key marker for TLS, may act as a freeradical scavenger and increase in response to oxidative stress. Additionally, urate crystals are known to activate inflammatory pathways and induce a systemic inflammatory response [30].

\section{Conclusions}

TLS is an oncological emergency that challenges providers to imply hypervigilance in monitoring fluid status, hemodynamics, clotting factors, electrolytes, and cytokines in order to expeditiously identify, respond, and, ultimately, prevent many devastating downstream consequences. Based on the latest studies, TLS-associated DIC as well as hypercytokinemia are novel therapeutic targets in treating this potentially fatal condition. We are in the process of developing a clinical study evaluating this novel strategy.

\section{Additional Information}

\section{Disclosures}

Conflicts of interest: In compliance with the ICMJE uniform disclosure form, all authors declare the following: Payment/services info: All authors have declared that no financial support was received from any organization for the submitted work. Financial relationships: All authors have declared that they have no financial relationships at present or within the previous three years with any organizations that might have an interest in the submitted work. Other relationships: All authors have declared that there are no other relationships or activities that could appear to have influenced the submitted work. 


\section{References}

1. Howard SC, Jones, DP, Pui CH: The tumor lysis syndrome. N Engl J Med. 2011, 364:1844-1854. 10.1056/NEJMra0904569

2. Cairo MS, Bishop M: Tumor lysis syndrome: new therapeutic strategies and classification . Br J Haematol. 2004, 127:3-11. 10.1111/j.1365-2141.2004.05094.x

3. Wilson FP, Berns JS: Tumor lysis syndrome: new challenges and recent advances . Adv Chronic Kidney Dis. 2014, 21:18-26. 10.1053/j.ackd.2013.07.001

4. Baeksgaard L, Sorensen JB: Acute tumor lysis syndrome in solid tumors -- a case report and review of the literature. Cancer Chemother Pharmacol. 2003, 51:187-192. 10.1007/s00280-002-0556-X

5. Méhes L, Udvardy M, Szász R, Rejtő L: The pathophysiology, clinical signs and therapy of urate nephropathy. Orv Hetil. 2007, 148:745-748. 10.1556/OH.2007.27989

6. Abu-Alfa AK, Younes A: Tumor lysis syndrome and acute kidney injury: evaluation, prevention, and management. Am J Kidney Dis. 2010, 55:1-13. 10.1053/j.ajkd.2009.10.056

7. Lotfi M, Brandwein JM: Spontaneous acute tumor lysis syndrome in acute myeloid leukemia? A single case report with discussion of the literature. Leuk Lymphoma. 1998, 29:625-628. 10.3109/10428199809050923

8. Firwana BM, Hasan R, Hasan N, Alahdab F, Alnahhas I, Hasan S, Varon J: Tumor lysis syndrome: a systematic review of case series and case reports. Postgrad Med. 2012, 124:92-101. 10.3810/pgm.2012.03.2540

9. Annemans L, Moeremans K, Lamotte M, et al.: Incidence, medical resource utilisation and costs of hyperuricemia and tumour lysis syndrome in patients with acute leukaemia and non-Hodgkin's lymphoma in four European countries. Leuk Lymphoma. 2003, 44:77-83. 10.1080/1042819021000054661

10. Gemici C: Tumour lysis syndrome in solid tumours . Clin Oncol (R Coll Radiol). 2006, 18:773-780. 10.1016/j.clon.2006.09.005

11. Persons DA, Garst J, Vollmer R, Crawford J: Tumor lysis syndrome and acute renal failure after treatment of non-small-cell lung carcinoma with combination irinotecan and cisplatin. Am J Clin Oncol. 1998, 21:426429. 10.1097/00000421-199808000-00024

12. Khalil A, Chammas M, Shamseddine A, Seoud M: Fatal acute tumor lysis syndrome following treatment of vulvar carcinoma: case report. Eur J Gynaecol Oncol. 1998, 19:415-416.

13. Burney IA: Acute tumor lysis syndrome after transcatheter chemoembolization of hepatocellular carcinoma . South Med J. 1998, 91:467-470. 10.1097/00007611-199805000-00012

14. Stoves J, Richardson D, Patel H: Tumour lysis syndrome in a patient with metastatic melanoma treated with biochemotherapy. Nephrol Dial Transplant. 2001, 16:188-189. 10.1093/ndt/16.1.188

15. Sewani HH, Rabatin JT: Acute tumor lysis syndrome in a patient with mixed small cell and non-small cell tumor. Mayo Clin Proc. 2002, 77:722-728. 10.4065/77.7.722

16. Busam KJ, Wolchok J, Jungbluth AA, Chapman P: Diffuse melanosis after chemotherapy-induced tumor lysis syndrome in a patient with metastatic melanoma. J Cutan Pathol. 2004, 31:274-280. 10.1111/j.03036987.2003.00154.x

17. Pession A, Melchionda F, Castellini C: Pitfalls, prevention, and treatment of hyperuricemia during tumor lysis syndrome in the era of rasburicase (recombinant urate oxidase). Biologics. 2008, 2:129-141. $10.2147 /$ btt.s1522

18. Cairo MS, Coiffier B, Reiter A, Younes A: Recommendations for the evaluation of risk and prophylaxis of tumour lysis syndrome (TLS) in adults and children with malignant diseases: an expert TLS panel consensus. Br J Haematol. 2010, 149:578-586. 10.1111/j.1365-2141.2010.08143.x

19. Coiffier B, Altman A, Pui CH, Younes A, Cairo MS: Guidelines for the management of pediatric and adult tumor lysis syndrome: an evidence-based review. J Clin Oncol. 2008, 26:2767-2778. 10.1200/JCO.2007.15.0177

20. Allen S, William A, Cassaday J, Wang J: Renal cell carcinoma with extensive rhabdoid features: case report of spontaneous tumor lysis syndrome and review of literature. Urol Res Ther J. 2018, 2:119.

21. Lovelace K, Vangessel Y, Asher LV, Vogel P: Spontaneous acute tumor lysis syndrome in a DBA/1J mouse: a case report and review. Toxicol Patho. 2003, 31:486-490. 10.1080/01926230390224674

22. Vogel P, Pletcher JM, Liang Y: Spontaneous acute tumor lysis syndrome as a cause of early deaths in shortterm carcinogenicity studies using P53 +/- mice. Vet Pathol. 2010, 47:719-724. 10.1177/0300985810363484

23. Calia CM, Hohenhaus AE, Fox PR, Meleo KA: Acute tumor lysis syndrome in a cat with lymphoma . J Vet Intern Med. 1996, 10:409-411. 10.1111/j.1939-1676.1996.tb02089.x

24. LaCarrubba AM, Johnson PJ, Whitney MS, Miller MA, Lattimer JC: Hypoglycemia and tumor lysis syndrome associated with peritoneal mesothelioma in a horse. J Vet Intern Med. 2006, 20:1018-1022. 10.1892/08916640(2006)20[1018:hatlsa]2.0.co;2

25. Mylonakis ME, Koutinas AF, Papaioannou N, Lekkas S: Acute tumour lysis syndrome in a dog with B-cell multicentric lymphoma. Aust Vet J. 2007, 85:206-208. 10.1111/j.1751-0813.2007.00127.x

26. Takeuchi N, Miyazawa S, Ohno Z, Yoshida S, Tsukamoto T, Fujiwara M: A Case of spontaneous tumor lysis syndrome in malignant melanoma. World J Oncol. 2016, 7:40-44. 10.14740/wjon970w

27. Kearney MR, Chen EY, Stenzel P, Corless CL, Deloughery TG, Zivney M, Lopez CD: Colorectal cancerassociated spontaneous tumor lysis syndrome: a case report and review of the current literature. J Gastrointest Cancer. 2019, 50:668-673. 10.1007/s12029-018-0102-7

28. Ito T, Ohta T, Narumi M, Sakaki H, Seino M, Sudo T, Nagase S: Tumor lysis syndrome associated with docetaxel and carboplatin in a case with recurrent endometrial cancer. Gynecol Oncol Rep. 2018, 24:21-23. 10.1016/j.gore.2018.02.005

29. Bien E, Maciejka-Kapuscinska L, Niedzwiecki M, et al.: Childhood rhabdomyosarcoma metastatic to bone marrow presenting with disseminated intravascular coagulation and acute tumour lysis syndrome: review of the literature apropos of two cases. Clin Exp Metastasis. 2010, 27:399-407. 10.1007/s10585-010-9335-y

30. Watanabe A, Tanaka R: Successful prevention of tumor lysis syndrome using recombinant urate oxidase in patient with metastasic and bulky prostate rhabdomyosarcoma. Case Rep Clin Med. 2014, 3:18-22.

31. Nguyen R, Ticona L: Spontaneous tumor lysis syndrome - a previously unrecognized complication of 


\section{Cureus}

untreated prostate cancer - and DIC as the initial presentation of metastatic prostate cancer. J Hosp Med. 2014, 9:3.

32. Teh R-W, Tsoi DT: Acute disseminated intravascular coagulation in neuroendocrine carcinoma . Case Rep Oncol. 2012, 5:524-529. 10.1159/000338401

33. Liu SK, Monaco WE: An extremely rare case of spontaneous tumor lysis syndrome . J Hosp Med. 2015, 10:596.

34. Barton JC: Tumor lysis syndrome in nonhematopoietic neoplasms . Cancer. 1989, 64:738-740. 10.1002/10970142(19890801)64:3<738::aid-cncr2820640328>3.0.c0;2-z

35. Hijiya N, Metzger ML, Pounds S, et al.: Severe cardiopulmonary complications consistent with systemic inflammatory response syndrome caused by leukemia cell lysis in childhood acute myelomonocytic or monocytic leukemia. Pediatr Blood Cancer. 2005, 44:63-69. 10.1002/pbc.20192

36. Nakamura M, Oda S, Sadahiro T, Hirayama Y, Tateishi Y, Abe R, Hirasawa H: The role of hypercytokinemia in the pathophysiology of tumor lysis syndrome (TLS) and the treatment with continuous hemodiafiltration using a polymethylmethacrylate membrane hemofilter (PMMA-CHDF). Transfus Apher Sci. 2009, 40:41-47. 10.1016/j.transci.2008.11.004

37. Soares M, Feres GA, Salluh JI: Systemic inflammatory response syndrome and multiple organ dysfunction in patients with acute tumor lysis syndrome. Clinics (Sao Paulo). 2009, 64:479-481. 10.1590/s180759322009000500016

38. Mirrakhimov AE, Voore P, Khan M, Ali AM: Tumor lysis syndrome: a clinical review . World J Crit Care Med. 2015, 4:130-138. 10.5492/wjccm.v4.i2.130

39. Schonbohn H, Schuler M, Kolbe K, Peschel C, Huber C, Bemb W, Aulitzky WE: Plasma levels of IL-1, TNF alpha, IL-6, IL-8, G-CSF, IL1-RA during febrile neutropenia: results of a prospective study in patients undergoing chemotherapy for acute myelogenous leukemia. Ann Hematol. 1995, 71:161-168. 10.1007/BF01910312

40. Hsu HC, Lee YM, Tsai WH, Jiang ML, Ho CH, Ho CK, Wang SY: Circulating levels of thrombopoietic and inflammatory cytokines in patients with acute myeloblastic leukemia and myelodysplastic syndrome. Oncology. 2002, 63:64-69. 10.1159/000065722 